\title{
,ance \\ Optimization of a Mobile Energy Storage Network
}

\author{
Luiz Eduardo Cotta Monteiro ${ }^{1, *}$, Hugo Miguel Varela Repolho ${ }^{1}$, Rodrigo Flora Calili ${ }^{2, *}$ (D), \\ Daniel Ramos Louzada ${ }^{2}$, Rafael Saadi Dantas Teixeira ${ }^{2}$ and Rodrigo Santos Vieira ${ }^{2}$
}

1 Industrial Engineering Department, Pontifical Catholic University of Rio de Janeiro, Rio de Janeir 22451-900, Brazil; industrial@puc-rio.br

2 Post Graduate Program in Metrology, Pontifical Catholic University of Rio de Janeiro, Rio de Janeiro 22451-900, Brazil; louzada@puc-rio.br (D.R.L.); metrologia@puc-rio.br (R.S.D.T.); rodrigo.vieira@solarmatrix.com.br (R.S.V.)

* Correspondence: luizmonteiro@aluno.puc-rio.br (L.E.C.M.); calili@puc-rio.br (R.F.C.)

check for updates

Citation: Monteiro, L.E.C.; Repolho, H.M.V.; Calili, R.F.; Louzada, D.R.;

Teixeira, R.S.D.; Vieira, R.S.

Optimization of a Mobile Energy

Storage Network. Energies 2022, 15,

186. https://doi.org/10.3390/

en15010186

Academic Editor: Andrea Frazzica

Received: 25 November 2021

Accepted: 23 December 2021

Published: 28 December 2021

Publisher's Note: MDPI stays neutral with regard to jurisdictional claims in published maps and institutional affiliations.

Copyright: (C) 2021 by the authors. Licensee MDPI, Basel, Switzerland. This article is an open access article distributed under the terms and conditions of the Creative Commons Attribution (CC BY) license (https:// creativecommons.org/licenses/by/ $4.0 /)$.

\begin{abstract}
This paper introduces the mobile battery network for electronic devices through powerbanks in a city, and proposes an optimization model to find the optimum site and set-up of the network considering costumers demand, logistics components, the batteries degradation, and terminal's charger regime. To this end, a series of degradation tests were carried out on lithium-ion batteries, in four different charger regimes, in which the battery voltage amplitude and the charging electric current were varied. The results of these tests were incorporated into the optimization model as the depreciation rate and charge time over battery life. The mathematical modeling innovates by including new components designed specifically for this new problem: battery availability according to charging time; different types of customer service; objective function modeling that includes the logistical costs of battery relocation, terminal maintenance, and battery depreciation. The results indicate that the network performance using batteries in the fastest charging configuration tends to have a positive impact on their efficiency and profitability. The model can be used as a reference for other applications that require recharge points that enable the use of mobile batteries, such as electric scooters, electric bicycles, and drones, among others.
\end{abstract}

Keywords: optimization model; lithium-ion batteries; powerbank network; state of charge; destructive tests

\section{Introduction}

The growth of Information and Communication Technologies has caused profound changes in the city environments and made possible the emergence of new business models. A relevant characteristic that can be identified in some of these models concern the concept of Product as a Service (PaaS), in which a client, instead of buying (and own a personal product), purchases the service of a company that offers access to a physical product or a specific service [1].

Following this concept, a new business model is being developed to promote access to a network of battery recharger terminals distributed throughout the city of Rio de Janeiro. Instead of purchasing and owning personal rechargeable batteries (powerbanks), users can take a fully charged powerbank from one of the city's terminals and return it to another terminal for their convenience and mobility. The concept is to create a network of mobile energy to support the increasing utilization of smartphones and mobile devices around the urban centers. The management of this type of network presents some challenges related to the optimization of the terminal network and battery performance, reduction of costs, and service-level improvement.

This paper aims to develop an optimization model to define a mobile battery network for electronic devices through powerbanks in a city. The proposed optimization model includes the logistics component and technical component linked to batteries degradation 
and charging terminals. A mixed integer programming model (MIP) is developed and combines strategic network location and sizing decisions (where to install and the capacity of the terminals) with operational decisions (allocation and reallocation of batteries at the terminals along the period). Laboratory tests with lithium-ion batteries similar to those used in the network were carried out in four different voltage and electric current configurations to measure the degradation rate and the performance of the batteries in terms of charge and discharge time. These results are embedded into the model as the parameters of the depreciation rate and the charging and discharging times of the batteries along the period.

The main contributions of this research are the following five. (i) It presents the mobile battery network for electronic devices through power banks. (ii) It proposes an optimization model, which combines some literature elements related to electric vehicle networks and bicycle-sharing networks, including new components designed specifically for this new problem, such as battery availability according to charging time, different types of customer service according to battery rental time, objective function modeling that includes the logistical costs of battery relocation and terminal maintenance, and battery depreciation. (iii) It performs laboratory tests with lithium-ion batteries and incorporate the results into the model. (iv) The model is applied to a case study using real data collected by a network of terminals located in the city of Rio de Janeiro. (v) We analyze our solutions and provide some insight into strategic and operational decisions to improve network performance. The paper is organized as follows: the next section presents the Material and Methods, including a literature review, the problem definition, and model formulation. In Section 3, we present a case study based in real data collected by a terminal network located in Rio de Janeiro city. The experimental results are presented in Section 4 . Section 5 presents the discussions and Section 6 the conclusions.

\section{Materials and Methods}

In this section, we present how the data for the model proposition were collected. In addition, the paths chosen for designing the proposed model are shown, based on the gap found in the literature. First, there was a deep analysis of existing documents in the literature related to the problem to be solved, "to develop an optimization model to define the mobile battery network for electronic devices through powerbanks in a city". The literature review consisted of two lines of investigation: (i) optimization models related to electric vehicles networks with battery swap infrastructures and bike-sharing networks and (ii) estimation models of lithium-ion batteries state of the health for smartphones. With the results of this investigation, it was possible to formulate the optimization model, based on integer programming. Furthermore, some tests on lithium-ion batteries were carried out in the laboratory, as these data were necessary to run the proposed model. In the following sections, each one of these processes is better explained.

\subsection{Literature Review}

As the mobile battery network for electronic devices through energy banks is a new kind of business model, all efforts have been made to find similar models in the scientific literature. To the best of our knowledge, we have not identified any similar case, so we searched for works that approach optimization models in networks that have similar characteristics to the powerbank network. In this context, optimization models applied to networks of battery swap and charging infrastructures for electric vehicles (EVs) and to bicycle-sharing networks were researched.

Bike-sharing networks present similar dynamics to powerbank network: bicycles are allocated to stations or docks with a restricted capacity; bicycles are rented by a defined time, picked up, and returned at the same or at a different station; the geographic location of the stations is related to the expected demand; and the allocation and reallocation of bicycles in the network must be optimized to meet the demand and reduce costs. In the case of electric vehicles networks, although it is more common to find models of recharging 
vehicle's batterie's infrastructures, some models consider the possibility of a battery swap at stations, which is similar to the context of the power bank network.

During the literature search in the scientific base Scopus and in the patent base Derwent Innovations Index (DII), the following keywords were used to filter our search: "Battery swap", "Logistic", "Demand", "Lithium battery", "Destructive tests", "State of charge", "State of health", and "Degradation". The combination of these keywords and the number of associated scientific papers can be seen in Table 1.

Table 1. Keywords and number of works and patents identified in the literature search.

\begin{tabular}{cccc}
\hline$\#$ & Key Words & Paper & Patent \\
\hline 1 & "Battery swap" AND “Logistic" & 0 \\
2 & "Battery swap" AND "Demand" & 3 \\
3 & "Lithium battery" AND "Destructive tests" & 43 & 0 \\
4 & "Lithium battery" AND "State of charge" & 1138 & 286 \\
5 & "Lithium battery" AND "State of health" & 220 & 35 \\
6 & "Lithium battery" AND "Degradation" & 1253 & 202 \\
7 & \#1 AND \#2 & 2 & 0 \\
8 & \#3 AND \#4 & 0 & 0 \\
9 & \#5 AND \#6 & 38 & 1 \\
10 & \#1 AND \#2 AND \#3 AND \#4 & 0 & 0 \\
\end{tabular}

Table 1 shows the number of papers and patents identified with the keywords crossing, evidencing a gap in the literature and reinforcing the contribution of the present work. In the next subsections, the main related works identified in the literature are described and analyzed.

Optimization Models Related to Electric Vehicle Networks with Battery Swap Infrastructures and Bike-Sharing Networks

The infrastructure of battery charging and battery swap facilities for electric vehicles in a long-distance corridor is analyzed in [2,3]. The non-linear mathematical model used has the objective of minimizing the total costs, which are represented by installation costs (associated to the size, the station's electrical power, and the number of charging points) and battery costs, which vary depending on its storage capacity. This model assumes the possibility of locating stations only at equidistant points on a single segment of a road.

Two robust optimization models applied to the planning process for deploying batteryswapping infrastructure is developed in [4]. The first model aims to minimize total costs and the second aims to maximize the return on investment (ROI). The first model has two stages: in stage 1, the location of the battery exchange stations is defined, and in stage 2 , where demand is known, the decision of the quantity of batteries in each station is taken in order to meet a given service level. The problem is modeled as a Mixed-Integer Second-Order Cone Program (MISOCP). The models are applied to the road network in San Francisco Bay, USA, and different scenarios of electric vehicles are assumed in the network, ranging from 50 to 1400 EVs. The results show that technological advances-mainly the reduction of the recharging time-tend to support the project's viability and the ROI increase.

A mathematical model for locating battery swap stations on an electric bus network (e-bus) is developed in [5]. The study analyzes three different ways of recharging batteries in electric vehicles: slow mode, fast mode, and battery swap mode. In the studied e-bus network, the authors identify the battery swap mode as the most appropriate for installation. The objective function is to minimize the total cost considering the construction, operation, and transportation cost. The model is solved by a particle swarm algorithm and is applied to the bus network in the city of Nanjing, China.

A location-routing problem with intra-route facilities (LRPIF) is presented in [6]. The model is an adaptation between the Facility Location Problem (FLP) and Vehicle Routing Problem (VRP) and its main differential is to consider simultaneously the decision 
of location and route. The objective function is to reduce total costs, considering the vehicles traveling and installations costs. The solution method applied is an Adaptive Large Neighborhood Search (ALNS) algorithm based on the Large Neighborhood Search (LNS) metaheuristic.

A model developed in [7] presents the design of an infrastructure network for battery swap services for electric vehicles, considering customer satisfaction in terms of the reach anxiety (concern that the EV battery has no autonomy to reach the destination) and anxiety of loss (associated with the desire not to carry or exchange a battery that still has a reasonably high charge). The problem is formulated as a non-linear model. Two scenarios are simulated: a deterministic scenario and a fuzzy scenario, for which the degree of customer satisfaction is formulated as a trapezoidal fuzzy variable. As a solution method, the authors use a combination of the Taboo Search and Greedy Randomized Adaptative Search Procedure (GRASP) heuristics. The results show that the location of stations on the busiest roads provides a better balance between the profit generated and customer satisfaction, while the roads with less movement are not able to sustain this balance.

A model for locating charging stations and replace batteries in a network of electric scooters is developed in [8]. A maximum coverage model is used as a reference for mathematical modeling and the multi-objective function seeks to minimize installation costs and maximize the number of customers served. The study considers two installation costs regarding two types of stations (recharging station or battery swap station) as a function of two population density profiles, in which the higher density areas have higher costs. The model is applied to the city of Taichung, Taiwan. The results show that in the peripheral areas, with lower population densities, charging stations are prioritized, while in the central regions (with higher density), the battery swap stations increase importance along with the charging stations.

A hub location inventory model that aims to design the infrastructure of a bicyclesharing network is developed in [9]. The model defines the stations' location cycle paths to interconnect the stations and the bike demand. Bicycle stations are described as hubs that connect demand points (residential, commercial areas, or intermodal transport stations). The integer programming model does not consider the dynamics of bicycle withdrawals and returns throughout the day, treating the expected daily demand in a static way. The model also does not consider the possibility of withdrawing and returning bicycles at the same station. The objective function seeks to minimize network costs, such that all expected demand is covered.

A maximum coverage model, developed in [2], is applied to a bicycle-sharing network with the objective function of maximizing the covered demand. The model aims to define the stations' locations and capacity, the number of bicycles in the network, and the relocation of the bicycles at the end of the period. The model considers a one-day operation discretized in five subperiods. The objective function does not consider the costs of the system and budget is included as a constraint. A case study is carried out with the application of the model in the city of Coimbra, Portugal, under four budget scenarios.

A framework to optimize the location of stations in a bicycle-sharing network is presented in [10]. Two alternatives of integer programming models are applied: a P-Median model (which seeks to minimize costs in function of the distance between stations and users) and a maximum coverage model that seeks to maximize the demand covered by a predefined number of stations. The decision is to locate the stations and the model does not make decisions related to the capacity of the stations and the quantity of bicycles needed to support the network. The results indicate that the P-Median model has solutions in which the stations are spatially more distributed in the city, providing better equity in terms of service distribution, while the maximum coverage model tends to concentrate the location of the stations in areas of great demand. The model is applied in the city of Seoul, Korea.

A model to optimize the relocation of bicycles between stations in a bike-sharing network based on the demand forecast (the inventory at the stations) and the routes of the vehicle that replace the bicycles is proposed in [11]. The problem is formulated as a 
multi-commodity flow network in a non-linear model and later reformulated as an integer programming model. The objective function minimizes the travel costs of the vehicle that reallocates the bicycles between stations and minimizes the users' dissatisfaction level expressed in terms of withdrawals or returns not met on the network. The model's decisions are limited at the operational level to define the quantity of bicycles in each station and the strategy of relocating bicycles in the period, including the routing of the vehicle that makes the bicycles relocation.

A two-stage stochastic model and a multi-stage model with the objective of determining the initial allocation of bicycles at the stations of a bike-sharing network is developed in [12]. The objective function is to minimize the total costs of the system. The two-stage model uses the single period of a day, and the multi-stage model discretizes a day into three sub-periods: morning, afternoon, and night. The model's stochasticity is represented by different demand scenarios for bicycle withdrawals created with the Monte Carlo simulation method, assuming four different probability distributions and using demand data from a real network. The model is applied to a bike-sharing network in Bergamo (Italy) consisting of 22 stations. The model considers the location and capacity of network stations as pre-defined parameters, limiting the decision variable to the quantity of bicycles allocated at the beginning of the day and the quantity reallocated between stations at the end of the period.

Regarding the researched optimization models, a significant difference was observed for the electric vehicle and bike models. In the case of the electric vehicle models, most networks consider simultaneously the possibility of swapping and recharging batteries, giving it a significant relevance to the infrastructure's construction costs (much more complex and costly than in the case of the powerbank network). Among the bike-sharing models, the capillarity of the network is more significant and the dynamics of pickup and return of bicycles at stations can be approximated to the powerbank network. The development of the new optimization model uses as a reference the maximum coverage location model of bike-sharing systems presented by [2] and include new components specifically designed for this new problem, such as availability of batteries according to the charging time, different types of customer service according to the battery rental time, and objective function modeling, which includes the logistical costs of reallocating batteries, maintenance of terminals, and depreciation of batteries in the system. The new model is detailed in Sections 2.2 and 2.3.

Despite research into hydrogen and fuel cells, which promise to be the next generation of mobile energy storage networks, nowadays, lithium-ion batteries are the best choice for promoting mobile electric power, since they have a high energy density and reliability. The lithium-ion batteries features have significant influences in the network performance. An important feature of batteries is the State of Health $(\mathrm{SOH})$, which evaluates, in percentages, the useful life of the battery, and it is directly influenced by its components (anode, cathode, and electrolyte). There are many methods for assessing the health of a battery, each being based on parameters, such as electrical current, voltage, temperature, etc. [13]. Although many difficulties still remain, different studies are dealing with this problem. For example, a new resource extraction method for battery health indicators in general discharge conditions was proposed in [14], allowing the use of methods based on data such as linear regression, support vector machine, machine vector relevance, and Gaussian process regression (GPR) to predict battery $\mathrm{SOH}$. Another effective parameter for measuring the health of a battery is the State of Charge (SOC), which measures the percentage of the battery's electric charge capacity in relation to the maximum capacity. It is generally used to determine the change in battery capacity over time [15] and has been the aim of different works. A data-driven method based on Gaussian process regression was developed in [16] to better estimate a battery pack SOC, being able to approximate nonlinearity accurately, nonparametric modeling, and probabilistic predictions. In the context of everyday electronic equipment, this parameter is used to determine how much energy the batteries can supply before they are discharged. However, there are many other applications for charge status. Through the 
charge state curve, it is possible to evaluate the quality of the battery, making it possible to estimate its state of life. The state of life is an essential parameter to determine how many charges and discharges the batteries support before they stop working [17]. This curve has been widely studied in applications involving the use of batteries in electric vehicles, but there are not many studies in the literature that involve the use of batteries in electronic equipment, such as smartphones, for example. However, it is assumed that when a battery achieves a degradation of between $70 \%$ and $80 \%$, its usefulness for any application is significantly compromised.

In order to predict the battery state of health curve, it is necessary to estimate its state of charge curve. The current models for estimating the state of charge curve can be divided into five categories: conventional, adaptive filter algorithm, learning algorithm, non-linear observer, and other hybrid methods [13]. Each of them needs specific conditions for using the battery so that the estimate can be as accurate as possible. Therefore, a more comprehensive study is needed to estimate the state of charge curve in everyday applications of electronic equipment, in order to achieve a model with a suitable precision for the purpose of this study.

Most of the models available in the literature today are highly complex and have high computational costs. The review article published by [13] comprehensively analyzes the charge state estimate of the lithium-ion battery and its management system for future and sustainable applications in electric vehicles. The work highlights the challenges and factors crucial to the success of this technology. The review identifies that the state of charge is a key parameter, as it measures the remaining available energy in a battery, providing an idea of the charge/discharge strategies and protection of the battery against overcharging/excessive discharge. The study also indicates that the state of charge is an important parameter to assess the health status of the batteries. Another review document prepared by [18] presents a discussion on the main methods of calibration, regression, and modeling methods for validation in terms of precision and accuracy of estimates for the state of charge.

The review work carried out by [19] indicates that estimating the state of charge in real time is essential for the development of intelligent control systems for the energy battery status. The document presents a review of the main methods and models for state of charge estimation, identifying their concepts, applicability, and performance in real-time monitoring applications.

It is clear that knowing the SOC of a battery is important when designing its charger. Some authors [20] have proposed an active SOC controller (FC-ASCC), using Fuzzy logic to improve the charging behavior of a lithium-ion battery. A prototype of a lithium-ion battery charger with FC-ASCC is simulated and used to evaluate the expected performance of the charge. Experience has shown that the charging speed of the proposed charger, in comparison with the general ones, increases by about $23 \%$ without compromising its safety, allowing it to work in a safe charging area (SCA).

The literature is scarce in relation to the SOC curve estimation, regarding the application on smartphones and mobile devices. Nevertheless, such an estimate is very important to predict the batteries' $\mathrm{SOH}$ over time. In order to contribute to the analysis of technological options to estimate the state of charge curve and to evaluate the health status of lithium-ion batteries used in smartphones, tests and trials were carried out in laboratories with batteries similar to those used in the powerbank network. The methodology and results of these tests are described in Section 2.3. These results are incorporated into the optimization model as new parameters, such as depreciation rate and charge time over battery life, being part of the main contributions of this research.

\subsection{Optimization Model Formulation}

Integer Programming Formulation

A mixed integer programming model (MIP) is developed and combines strategic network location and sizing decisions (where to install and the capacity of the terminals) 
with operational decisions (allocation and reallocation of batteries at the terminals). The maximum coverage location model of bike-sharing systems presented by [2] is used as a reference for the new mathematical modeling that innovates by including new ingredients: battery recharge time, different types of customer service, charging system settings and battery performance, and a different Objective Function (OF) that seeks to maximize the economic performance of the network obtained from the differences between the revenue generated by the leasing of batteries and the logistical costs of reallocating batteries, maintenance of terminals, and depreciation of batteries in the system.

The model outputs are the optimal points for installing the terminals on the network, the capacity of each installed terminal, the number of batteries needed to supply the terminal network, and the number of batteries to be allocated and reallocated between each point over the period. The model inputs include the potential points for installing battery terminals, the demand forecast for the network points over the time period, the battery recharge time according to the service type and configuration of the charging system, the average revenue obtained from battery removal, the maximum and minimum capacity of the terminals, the fixed and variable costs of reallocating batteries, the maintenance costs of the terminals, the costs of depreciation of batteries (depending on charging system configuration), and the total number of terminals and batteries available for network implementation.

The model sets and indexes are described in Table 2. Table 3 presents the variables and each respective domain. The model input parameters are described in Table 4 . Index $i$ represents the set of candidate sites for installing terminals and index $t$ represents the set of time intervals in which the $\mathrm{T}$ period is discretized. Index s refers to the type of service, which is related to the time duration. The binary variable $Y_{i}$ indicates whether the terminal at point $\mathrm{i}$ is installed $(=1)$ or not $(=0)$.

Table 2. Sets, indexes, and domains.

\begin{tabular}{cccc}
\hline Sets & Simbols & Index & Domain \\
\hline Demand points & $\mathrm{J}$ & $\mathrm{i}, \mathrm{j}$ & $\{1 . . \mathrm{J}\} \in \mathbb{N}+$ \\
Time & $\mathrm{T}$ & $\mathrm{t}$ & $\{0 . . \mathrm{TT}\} \in \mathbb{N}+$ \\
Service type & $\mathrm{S}$ & $\mathrm{s}$ & $\{0 . . \mathrm{S}\} \in \mathbb{N}+$ \\
\hline
\end{tabular}

Table 3. Decision variables' definition.

\begin{tabular}{|c|c|c|}
\hline Variables & Definition & Domain \\
\hline$Y_{i}$ & $\begin{array}{l}\text { Binary variable, equal to } 1 \text { if a terminal at point } \\
\text { (i) is installed or equal to } 0 \text { if not }\end{array}$ & $\{0,1\}$ \\
\hline $\mathrm{R}_{\mathrm{ijt}}$ & $\begin{array}{l}\text { Number of charged batteries reallocated from } \\
\text { point (i) to point (j) during time period (t). }\end{array}$ & $\epsilon \mathbb{N}+$ \\
\hline $\mathrm{BC}_{\mathrm{it}}$ & $\begin{array}{l}\text { Number of charged batteries at point }(\mathrm{i}) \text { in the } \\
\text { beginning of time period }(\mathrm{t})\end{array}$ & $\epsilon \mathbb{N}+$ \\
\hline $\mathrm{B}_{\text {it }}$ & $\begin{array}{c}\text { Total number of batteries at point (i) in the } \\
\text { beginning of time period }(\mathrm{t})\end{array}$ & $\epsilon \mathbb{N}+$ \\
\hline $\mathrm{S}_{\mathrm{i}}$ & $\begin{array}{l}\text { Terminal Capacity at point (i) } \\
\text { (quantity of battery slots). }\end{array}$ & $\epsilon \mathbb{N}+$ \\
\hline $\mathrm{Tb}$ & Total number of batteries in the network & $\in \mathbb{N}+$ \\
\hline Tter & Total number of terminais in the network & $\epsilon \mathbb{N}+$ \\
\hline
\end{tabular}


Table 4. Model parameters.

\begin{tabular}{|c|c|c|}
\hline Parameters & Definition & Unity \\
\hline $\operatorname{Din}_{\mathrm{it}}^{\mathrm{s}}$ & $\begin{array}{l}\text { Demand of batteries return at point (i) in time }(\mathrm{t}) \text { for the } \\
\text { service type (s) }\end{array}$ & quantity \\
\hline Dout $_{\text {it }}$ & Demand of batteries withdrawal at point (i) in time (t) & quantity \\
\hline $\mathrm{k}$ & Subperiod (time interval used to discretize period TT) & time \\
\hline $\operatorname{tr}_{\mathrm{S}}$ & $\begin{array}{l}\text { Battery discharge time for each service type (s) } \\
\text { (expressed as " } \mathrm{k} \text { " integer unit) }\end{array}$ & time \\
\hline $\mathrm{TT}$ & Total time of the period (expressed as " $k$ " integer unit) & time \\
\hline Pm & Average revenue from each battery rental & $\mathrm{R} \$$ \\
\hline$S_{\max }$ & Maximum terminal capacity (slots) & quantity \\
\hline $\mathrm{S}_{\min }$ & Minimum terminal capacity (slots) & quantity \\
\hline Tbmax & Maximum number of batteries in the network & quantity \\
\hline Ttmax & Maximum number of terminals in the network & quantity \\
\hline $\mathrm{Crb}$ & Unit fixed cost for reallocating a battery & $\mathrm{R} \$$ \\
\hline Cvrb & Battery reallocation cost per kilometer & $\mathrm{R} \$$ \\
\hline Dist $_{\mathrm{ij}}$ & Distances matrix between each network points $(i, j)$ & kilometer \\
\hline Cfmt & Fixed maintenance cost per terminal in period TT & $\mathrm{R} \$$ \\
\hline Cvmt & $\begin{array}{l}\text { Variable maintenance cost per terminal in period TT (in } \\
\text { function of the number slots) }\end{array}$ & $\mathrm{R} \$$ \\
\hline $\mathrm{Cdb}$ & Battery depreciation unit cost in period TT & $\mathrm{R} \$$ \\
\hline
\end{tabular}

The OF is given by Equation (1). The revenue generated by users is calculated by multiplying the total number of leased batteries in the network (Dout ${ }_{i t}$ ) by the parameter $\mathrm{Pm}$ (average revenue obtained for each leased battery) and the binary variable $Y_{i}$. The cost of relocating batteries is represented by the fixed cost of reallocation (given by multiplying the fixed reallocation unit cost $\mathrm{Crb}$ by the total number of reallocations $\mathrm{R}_{\mathrm{ijt}}$ ) and the variable cost of reallocation (given by multiplying the unit cost of reallocation per $\mathrm{km}(\mathrm{Cvrb})$ by the total reallocations and their respective distances (Dist $\left.t_{\mathrm{ij}}\right)$. The cost of maintaining the network is calculated according to the number of installed terminals $Y_{i}$ and the capacity of the installed terminals $(\mathrm{Si})$. The cost of depreciation of the batteries is calculated by multiplying the total number of batteries in the network $\left(\mathrm{B}_{\mathrm{it}}\right)$ by the unit cost of depreciation in the period $(\mathrm{Cdb})$. Similar models applied to battery charging networks have not been identified in the literature. The mathematical model is described below:

$$
\begin{aligned}
& \text { Maximize } \mathrm{Z}= \\
& \sum_{\mathrm{i} \in \mathrm{J}} \sum_{\mathrm{t} \in \mathrm{T}}\left(\text { Dout }_{\mathrm{it}} \times \mathrm{Y}_{\mathrm{i}} \times \mathrm{Pm}\right)-\mathrm{Crb} \times \sum_{\mathrm{i} \in \mathrm{J}} \sum_{\mathrm{j} \in \mathrm{J}} \sum_{\mathrm{t} \in \mathrm{T}} \mathrm{R}_{\mathrm{ijt}}-\mathrm{Cvrb} \times \sum_{\mathrm{i} \in \mathrm{J}} \sum_{\mathrm{j} \in \mathrm{J}} \sum_{\mathrm{t} \in \mathrm{T}} \mathrm{R}_{\mathrm{ijt}} \times \text { Dist }_{\mathrm{ij}} \\
& -\mathrm{Cfmt} \times \sum_{\mathrm{i} \in \mathrm{J}} \mathrm{Y}_{\mathrm{i}}-\mathrm{Cvmt} \times \sum_{\mathrm{i} \in \mathrm{J}} \mathrm{Si}-\mathrm{Cdb} \times \sum_{\mathrm{i} \in \mathrm{J}} \mathrm{B}_{\mathrm{i}(\mathrm{t}=1)}
\end{aligned}
$$

Subject to:

$$
\begin{gathered}
\mathrm{S}_{\mathrm{i}} \leq \mathrm{Y}_{\mathrm{i}} \times \mathrm{S}_{\max }, \forall \mathrm{i} \in \mathrm{J} \\
\mathrm{S}_{\mathrm{i}} \geq \mathrm{Y}_{\mathrm{i}} \times \mathrm{S}_{\text {min }}, \forall \mathrm{i} \in \mathrm{J} \\
\mathrm{B}_{\mathrm{i}(\mathrm{t}=1)}=0.6 * \mathrm{~S}_{\mathrm{i}}, \forall \mathrm{i} \in \mathrm{J} \\
\mathrm{B}_{\mathrm{it}} \leq 0.8 \times \mathrm{S}_{\mathrm{i}}, \forall \mathrm{i} \in \mathrm{J}, \forall \mathrm{t} \in \mathrm{T} \\
\mathrm{B}_{\mathrm{it}} \geq 0.2 \times \mathrm{S}_{\mathrm{i}}, \forall \mathrm{i} \in \mathrm{J}, \forall \mathrm{t} \in \mathrm{T}
\end{gathered}
$$

$B_{i t}=B_{i(t-1)}-\operatorname{Dout}_{i(t-1)} Y_{i}+\sum_{s \in S} \operatorname{Din}_{i(t-1)}^{s} Y_{i}+\sum_{j \in J} R_{j i(t-1)}-\sum_{j \in J} R_{i j(t-1)}, \forall i \in J j \in J, t \in T \mid t \geq 2$

$$
\mathrm{BC}_{\mathrm{i} \mathrm{t}=1}=\mathrm{B}_{\mathrm{i}(\mathrm{t}=1)}, \forall \mathrm{i}
$$




$$
\begin{aligned}
& \mathrm{BC}_{\mathrm{i} t}=\mathrm{BC}_{\mathrm{i}(\mathrm{t}-1)}-\operatorname{Dout}_{\mathrm{i}(\mathrm{t}-1)} \mathrm{Y}_{\mathrm{i}}+\sum_{\mathrm{s} \in \mathrm{S}} \operatorname{Din}_{\mathrm{i}\left(\mathrm{t}-\mathrm{tr}^{\mathrm{s}}-1\right)}^{\mathrm{s}} \mathrm{Y}_{\mathrm{i}}+\sum_{\mathrm{j} \in \mathrm{J}} \mathrm{R}_{\mathrm{ji}(\mathrm{t}-1)}-\sum_{\mathrm{j} \in \mathrm{J}} \mathrm{R}_{\mathrm{ij}(\mathrm{t}-1)}, \forall \mathrm{i} \in \mathrm{J}, \mathrm{t} \in \mathrm{T} \\
& \text { BC }_{\mathrm{it}} \geq \text { Dout }_{\mathrm{it}} \mathrm{Y}_{\mathrm{i}}+\mathrm{R}_{\mathrm{ij} \mathrm{t}} \forall \mathrm{i}, \mathrm{j} \in \mathrm{J}, \forall \mathrm{t} \in \mathrm{T} \\
& \mathrm{Tb}=\sum_{\mathrm{i} \in \mathrm{J}} \mathrm{B}_{\mathrm{i}(\mathrm{t}=1)} \\
& \mathrm{Tb} \leq \mathrm{Tbmax} \\
& \text { Tter }=\sum_{i \in J} Y_{i} \\
& \text { Tter } \leq \text { Ttmax } \\
& \mathrm{Y}_{\mathrm{i}} \in\{0,1\}, \forall \mathrm{i} \in \mathrm{J} \\
& \mathrm{BC}_{\mathrm{it}}, \mathrm{B}_{\mathrm{it}}, \mathrm{S}_{\mathrm{i}}, \mathrm{R}_{\mathrm{ijt}} \in \mathrm{N} \forall \mathrm{i} \in \mathrm{J}, \forall \mathrm{j} \in \mathrm{J}, \forall \mathrm{t} \in \mathrm{T}
\end{aligned}
$$

The capacity of each terminal to provide batteries (quantity of slots) must be less than a maximum limit and greater than a minimum capacity limit, according to Constraints (2) and (3).

Equation (4) defines that at the beginning of the period $(t=1)$, the number of batteries available in the terminal (i) will be equal to $60 \%$ of their respective capacity, an approximate percentage of the current startup policy that uses approximately two-thirds of the capacity of the terminals at the beginning of the period. To ensure the movement of batteries between different terminals on the network with a satisfactory service level, it is necessary that each terminal always have a relative quantity of free slots available in order to make it possible to return batteries removed from other terminals. According to [2], in a bicycle-sharing network, experience indicates that the free space at stations should be approximately $25 \%$ of its capacity. In this sense, Equations (5) and (6) define that throughout the period, the availability of batteries in each terminal (i) must be less than $80 \%$ of its capacity and greater than $20 \%$ of its capacity. Thus, it is expected to guarantee a satisfactory service level, allowing the user to perform the pickup and return of batteries at any time (t). Equation (7) calculates the total number of batteries in the terminal over time $(\mathrm{t})$, making the balance of withdrawals, returns, and reallocations of batteries between terminals. Equation (8) defines that at the beginning of the period $(t=1)$, all batteries in the terminal are charged and available for withdrawal. Equation (9) defines the number of batteries charged and available for withdrawal at each terminal point (i) for every time ( $t$ ), making the balance between the quantity of batteries available at terminal (i) in the previous time $(t-1)$, batteries picked up from terminal (i) in the previous time $(t-1)$, batteries returned in terminal (i) in time $\left(t-\operatorname{tr}^{s}-1\right)$ already recharged and available for a new withdrawal, and the reallocated batteries that were removed and returned at terminal (i) in the previous time $(t-1)$. Equation (10) ensures that the number of batteries charged in each terminal (i) in each time interval $(t)$ must be greater than their respective demand for withdrawals $\left(\right.$ Dout $_{i t}$ ) added to the battery reallocations performed from station (i) at time ( $\mathrm{t}$ ). Constraint (11) defines the total number of batteries in the network. Equation (12) defines that the total number of batteries in the system cannot be greater than Parameter Tbmax. Equations (13) and (14) determine, respectively, the total number of terminals on the network and their upper limit, according to Parameter Ttmax. Equations (15) and (16) specify the decision variables domain.

\subsection{Lithium-Ion Batteries and Laboratory Tests}

Laboratory tests with lithium-ion batteries similar to those used in the network were carried out in four different voltage and electric current configurations, measuring the degradation rate and the performance of the batteries in terms of charge and discharge cycles. These results are incorporated into the model as the parameters of the depreciation rate and the charging and discharging cycles of the batteries along the period. The labora- 
tory tests were made based on a study presented at the 10th Brazilian Metrology Congress that addresses the development of a voltage curve prediction model for lithium-ion battery based on destructive tests. This study is described in the article by [21].

Measurements were made with 16 new batteries. The measurement system has a modular configuration, in which the 16 test batteries are grouped into four groups of four batteries each. The charge parameters are controlled by hardware or software. The parameters for each group are shown in Table 5. The measurements showed how the change in charge parameters influences the behavior of the batteries.

Table 5. Parameters used in each battery group.

\begin{tabular}{ccccc}
\hline Parameter & Group 1 & Group 2 & Group 3 & Group 4 \\
\hline $\mathrm{I}_{\mathrm{C}}$ & $1 \mathrm{~A}$ & $2 \mathrm{~A}$ & $2 \mathrm{~A}$ & $3 \mathrm{~A}$ \\
$\mathrm{~V}_{\mathrm{C}}$ & $4.1 \mathrm{~V}$ & $4.1 \mathrm{~V}$ & $4.2 \mathrm{~V}$ & $4.1 \mathrm{~V}$ \\
$\mathrm{~V}_{\mathrm{MIN}}$ & $3.3 \mathrm{~V}$ & $3.3 \mathrm{~V}$ & $3.3 \mathrm{~V}$ & $3.3 \mathrm{~V}$ \\
\hline
\end{tabular}

The parameters were chosen based on the different charging modes used on the market. The minimum discharge voltage was fixed at $3.3 \mathrm{~V}$ for all groups, aiming at a longer battery life. For all groups, the batteries charging occur in two different stages: the first with constant current and the second with constant voltage. The discharge phase starts at the end of the constant voltage charge stage, when the charging current is decreasing and reaches a value equal to $10 \%$ of the initial charging current (in the constant current charging stage). The charge current IC is the one that has the greatest influence on the battery life and, for this reason, it was used as a parameter to have a different value for each of the four test groups.

The measurements indicated that the charge parameters significantly change the behavior of the batteries over their useful life. Table 6 shows, for each Battery Group, the average number of cycles to the present measurement moment, the average cycle time, the average charge time, and the average charge capacity. As expected, Group 4 (3 A of current in the constant current phase) had a shorter time to charge the batteries. In this way, the number of cycles performed is higher than those performed by the other groups. In contrast, the charge retained by this group were the lowest recorded. Group 4 presents greater charging instability, due to the stress submitted to batteries in the constant current charging process.

Table 6. Average measurements of the four battery groups.

\begin{tabular}{ccccc}
\hline & Cicles Number & $\begin{array}{c}\text { Average Cycle } \\
\text { Time (h) }\end{array}$ & $\begin{array}{c}\text { Average Charge } \\
\text { Time (h) }\end{array}$ & $\begin{array}{c}\text { Average Capacity } \\
\text { (mAh) }\end{array}$ \\
\hline Group 1 & 215 & 6.38 & 4.34 & 3761.25 \\
Group 2 & 382 & 3.60 & 1.87 & 3131.86 \\
Group 3 & 305 & 4.53 & 2.29 & 4004.69 \\
Group 4 & 473 & 3.00 & 1.66 & 2858.47 \\
\hline
\end{tabular}

Group 3 had the highest average charge capacity recorded. Having as the only different parameter from Group 2 the voltage limit in the constant voltage phase (4.2 Volt), it is concluded that this is a decisive parameter for the capacity of the batteries to retain charge. However, Group 3 batteries take longer to charge when compared to Group 2 batteries. This is due to the higher voltage limit (4.2 Volt), which forces a longer charging process during the constant voltage phase, just when charging is slower.

The charging time observed in Group 2 is slightly higher than that recorded by Group 4 and considerably less compared to Group 1 . This indicates that $2 \mathrm{~A}$ of electric current in the constant current phase is a good value for charging the batteries, as the charging time it is not very long and the batteries are not subjected to high stress. 
The average degradation ratio of the batteries of the four Groups are shown in Table 7. The degradation was calculated for 50, 100, 150, 200, 250, 300, 350, and 400 cycles. No battery has any sign of considerable degradation. This is in line with what is presented in the literature. More completed cycles will be needed to have a deeper analysis of the degradation of the 16 batteries. However, it is possible to observe that the Group 3 batteries are the ones with the higher degradation. This indicates that charging lithium-ion batteries to their maximum value causes their battery life to decrease more rapidly. Even with the great charge instability observed in the batteries of Group 4, a considerable degradation rate was not noticed in the batteries of this group.

Table 7. Average degradation ratio for batteries of the four groups.

\begin{tabular}{ccccccccc}
\hline Degradation Ratio & 50 Cicles & 100 Cicles & 150 Cicles & 200 Cicles & 250 Cicles & 300 Cicles & 350 Cicles & 400 Cicles \\
\hline Group 1 & 0.98 & 0.96 & 0.94 & 0.92 & - & - & - & - \\
Group 2 & 0.97 & 0.98 & 0.95 & 0.94 & 0.93 & 0.95 & 0.94 & - \\
Group 3 & 0.99 & 0.97 & 0.94 & 0.92 & 0.91 & 0.90 & - & - \\
Group 4 & 1.00 & 0.99 & 0.99 & 0.99 & 0.99 & 0.98 & 0.92 & 0.93 \\
\hline
\end{tabular}

It is important to notice that the blanks in Table 7 show that the batteries of different groups reached different number of cycles due to the different times taken to carry out the charging and discharging cycles.

\section{Case Study}

A case study was carried out with a startup located in Rio de Janeiro that developed the business model and has, until now, implemented a powerbank network with 42 terminals installed in the cities of Rio de Janeiro and Niteroi. Figure 1 shows where the terminal points were installed. Real data from the network containing 8222 operations registered between 7 August 2017 and 29 August 2019 were used to simulate different demand scenarios using the Monte Carlo Method. Table 8 describes the local types with installed terminals on the network and the percentage of withdrawals per locale. The company offers three types of services: free (battery rental for up to $30 \mathrm{~min}$ ), short-term paid service (battery rental for up to $4 \mathrm{~h}$ ), and long-term paid service (battery rental for up to $24 \mathrm{~h}$ ). Figure 2 shows the percentage distribution of withdrawals by type of service and by time of day on the network. Red bullets indicate the places where terminal points are installed.

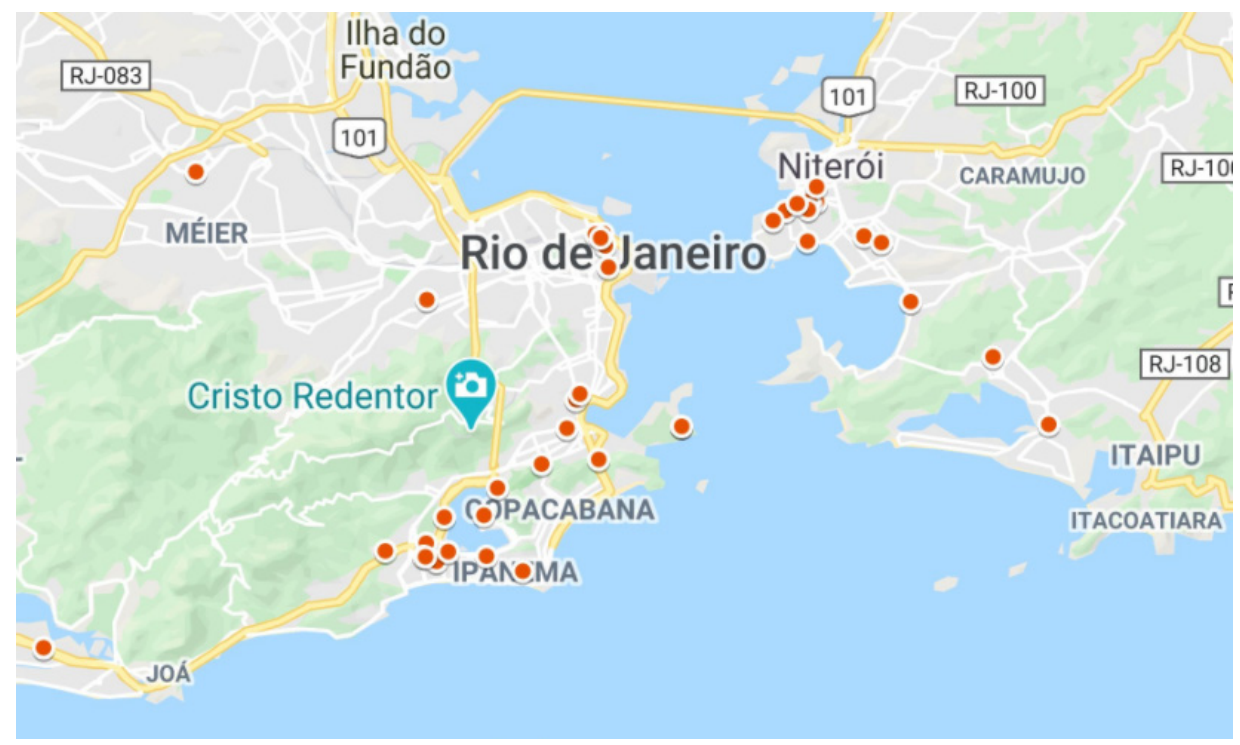

Figure 1. Terminal points installed. 
Table 8. Local types and percentage of withdrawals per locale.

\begin{tabular}{cccc}
\hline Local Type & $\begin{array}{c}\text { Quantity on } \\
\text { Network }\end{array}$ & $\begin{array}{c}\text { Total Percentage of } \\
\text { Withdrawals from } \\
\text { the Network }\end{array}$ & $\begin{array}{c}\text { Percentage of Withdrawals } \\
\text { by Unit Point from the } \\
\text { Network }\end{array}$ \\
\hline Fitness Center & 1 & $7.7 \%$ & $7.7 \%$ \\
\hline Bar/Restaurant & 13 & $43.8 \%$ & $3.4 \%$ \\
\hline Firm/Cowork & 4 & $5.7 \%$ & $1.4 \%$ \\
\hline $\begin{array}{c}\text { Shop in } \\
\text { transport station }\end{array}$ & 1 & $4.6 \%$ & $4.6 \%$ \\
\hline Shopping Center & 5 & $4.2 \%$ & $0.8 \%$ \\
\hline Turistic Spot & 2 & $3.1 \%$ & $1.5 \%$ \\
\hline Gas Station & 8 & $12.8 \%$ & $1.6 \%$ \\
\hline Supermarket & 2 & $0.6 \%$ & $0.3 \%$ \\
\hline University & 6 & $17.6 \%$ & $2.9 \%$ \\
\hline
\end{tabular}

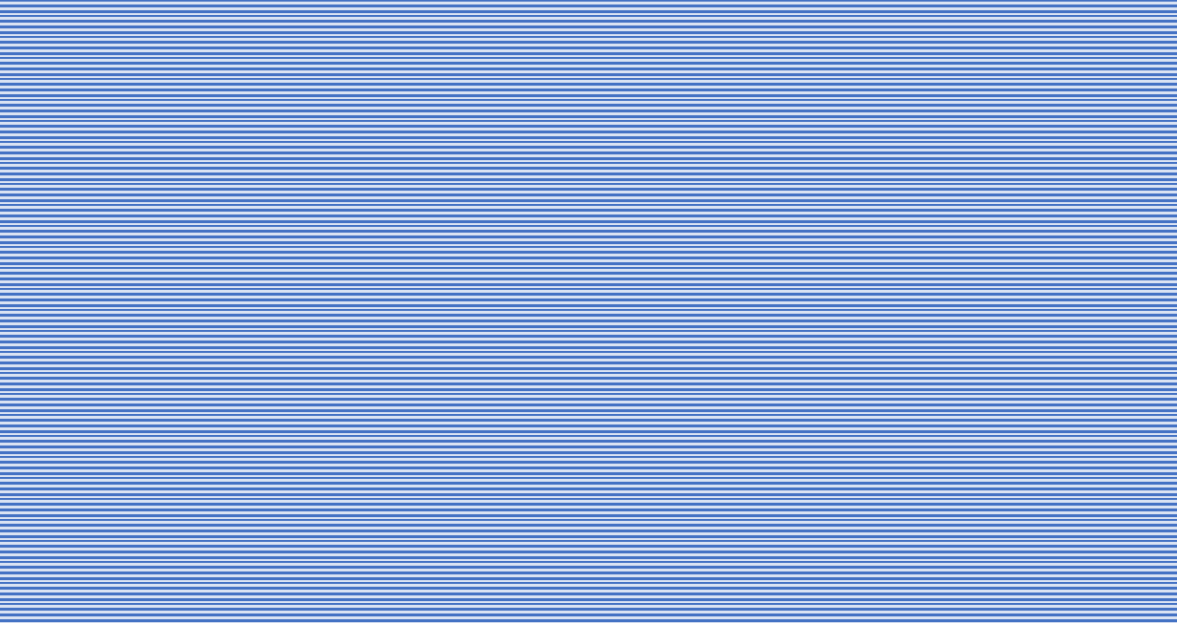

$\longrightarrow$ Free service (\%) $\longrightarrow$ Payed (short duration) (\%) $\longrightarrow$ Payed (long duration) (\%)

Figure 2. Percentage distribution of withdrawals per type of service and per hour of the day.

The percentage distribution of withdrawals per locale, per type of service, and per hour of the day were used to simulate five different demand scenarios using the Monte Carlo Method. The models were implemented simulating the operation of one-day discretized in 48 periods of $30 \mathrm{~min}$ and using the five different demand scenarios and the four different voltage and electrical current settings used in laboratory tests. It was assumed a maximum limit of 20 points for the installation of terminals (Ttmax) and a limit of the number of batteries of 400 batteries for supplying the network (Tbmax). The maximum capacity of the terminals was set to be equal to 36 slots.

The storage capacity of the batteries, the charge level of the batteries at the moment of their return to the terminal, and the time required to recharge the battery at the optimum level in the terminal so that it is again available for rental are important factors that influence the performance of the battery network. The results of laboratory tests with lithium-ion batteries as described in Section 2.3 were used to estimate the behaviors parameters of the batteries in the optimization model. Figures 3 and 4 show the average charge capacity and the average charge and discharge time in each group of batteries, respectively. 


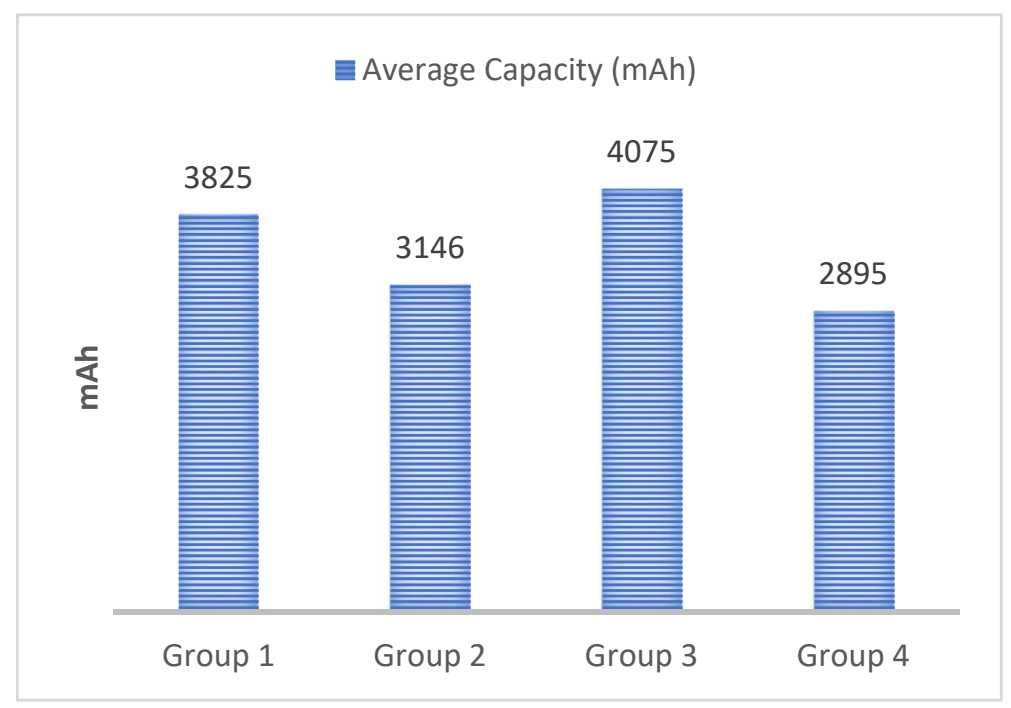

Figure 3. Average charge capacity for each battery group.

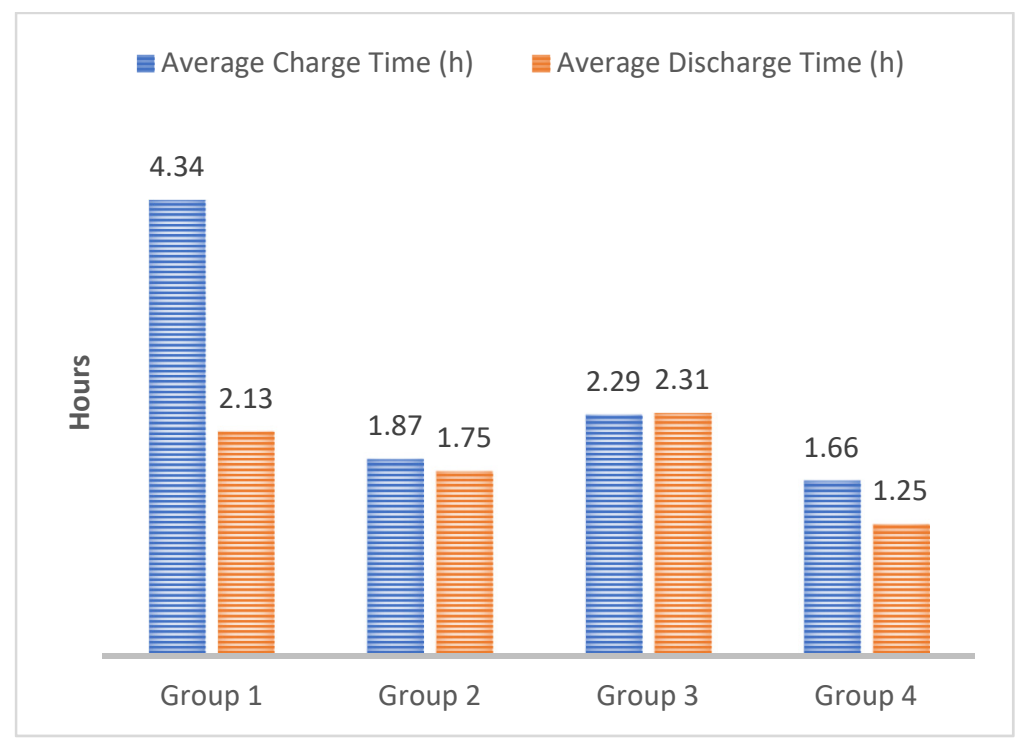

Figure 4. Average charge and discharge time for each battery group.

The analysis of the network database enables to evaluate the behavior of the network demand in three different types of services ("free", "paid short term", and "paid long term") classified according to the battery rental time, as described in Figure 2. The duration a battery is used influences its charge level when it is returned to the terminal. In this way, it can be assumed that a free service (battery rental within $30 \mathrm{~min}$ ) will result in the return to the terminal of a battery with a high level of charge; a "short-term paid" service will result in a battery with a medium charge level being returned to the terminal and a "longterm paid" service will result in a fully discharged battery being returned to the terminal. Considering this aspect and the results of laboratory tests with the measurement of the average recharge and discharge time for each of the four battery groups, the parameters of recharge time by service type $\left(\operatorname{tr}_{\mathrm{s}}\right)$ were estimated for the optimization model, as described in Table 9. 
Table 9. Battery recharge time for each group in different service types.

\begin{tabular}{ccccc}
\hline \multirow{2}{*}{ Service Type } & \multicolumn{4}{c}{ Battery Recharge Time (h) } \\
\cline { 2 - 5 } & Group 1 & Group 2 & Group 3 & Group 4 \\
\hline 1. Free (use up to 30 $\mathrm{min}$ ) & 0.68 & 0.33 & 0.31 & 0.42 \\
\hline 2. Payed (use up to 4 h) & 1.35 & 0.67 & 0.62 & 0.83 \\
\hline 3. Payed (use up to 24 h) & 4.34 & 1.87 & 2.29 & 1.66 \\
\hline
\end{tabular}

The energy storage capacity of batteries tends to deteriorate over time depending on the number of charge cycles. A more accelerated deterioration of the battery's storage capacity implies a faster depreciation of the battery, influencing in economic terms a higher depreciation rate of the battery asset. The test results of the degradation rate of each group of batteries are used to estimate the parameter of the depreciation rate of the batteries in the optimization model by adding the average depreciation rate of batteries ( $\mathrm{R} \$ 0.14$ per day) to its value multiplied by the respective battery degradation rate of each battery group. Table 10 presents the estimated values of the depreciation rate for each group of batteries.

Table 10. Battery depreciation parameter as a function of the degradation ratio.

\begin{tabular}{ccc}
\hline Charge Configuration & Degradation Ratio & Unit Depreciation Cost \\
\hline Group 1 & $5.84 \%$ & 0.148 \\
\hline Group 2 & $4.76 \%$ & 0.147 \\
\hline Group 3 & $6.22 \%$ & 0.149 \\
\hline Group 4 & $2.29 \%$ & 0.143 \\
\hline
\end{tabular}

\section{Results}

The optimization model was implemented in AIMMS software version 3.14. The implementation was performed with the five different demand scenarios created by the Monte Carlo simulation method and the four different battery charging system configurations used in the laboratory tests. The model was solved using the CPLEX 12.6 solver with an execution time limited to $1200 \mathrm{~s}$. Table 11 presents the results of the Objective Function $(\mathrm{OF})$, number of batteries used to supply the network, estimated gap between the OF result and the OF optimal value, and model execution time for each scenario and each group of batteries. The best OF result for each scenario is highlighted in bold.

Comparing the results between the groups, it is noted that Group 4 presented a better OF performance in all scenarios, which can be explained by the fact that it has the lowest battery charging time in the system, generating greater network efficiency. Although Group 4 has a faster discharge time, its impact on the battery depreciation parameter does not make such a significant difference when compared to other groups, as can be seen in Figure 4 and Table 10, respectively. It should also be noted that Group 1, which has the largest recharge time among the batteries groups, obtained the worst result regarding OF value and also the largest quantity of batteries used among all scenarios. The optimal value was obtained only for one instance (Group 1, scenario 1). In all other instances, although the optimal value was not reached, the gap was very small, ranging between $0.01 \%$ and $0.17 \%$, with an average gap of $0.05 \%$. It should be noted that the reference of the discharge times of batteries used in the model was obtained from tests performed in the laboratory and does not necessarily describe the actual discharge behavior in a common use of a customer. This is a characteristic that was not included in this first model, but that can be addressed in a future extension of the model. 
Table 11. Model results: objective function, OF gap, number of batteries, and runtime.

\begin{tabular}{|c|c|c|c|c|c|}
\hline $\begin{array}{l}\text { Demand } \\
\text { Scenarios }\end{array}$ & $\begin{array}{l}\text { Charge System } \\
\text { Configuration }\end{array}$ & OF & Gap & $\begin{array}{c}\text { Quantity of } \\
\text { Batteries }\end{array}$ & $\begin{array}{c}\text { Execution } \\
\text { Time (s) }\end{array}$ \\
\hline \multirow{4}{*}{ Scenario 1} & Group 1 & 882.41 & OPT & 70 & 836 \\
\hline & Group 2 & 883.8181 & $0.05 \%$ & 67 & 1200 \\
\hline & Group 3 & 883.8177 & $0.06 \%$ & 62 & 1200 \\
\hline & Group 4 & 883.951 & $0.02 \%$ & 63 & 1200 \\
\hline \multirow{4}{*}{ Scenario 2} & Group 1 & 930.9611 & $0.04 \%$ & 67 & 1200 \\
\hline & Group 2 & 931.9044 & $0.03 \%$ & 61 & 1200 \\
\hline & Group 3 & 931.7824 & $0.03 \%$ & 61 & 1200 \\
\hline & Group 4 & 932.111 & $0.03 \%$ & 63 & 1200 \\
\hline \multirow{4}{*}{ Scenario 3} & Group 1 & 858.4268 & $0.06 \%$ & 87 & 1200 \\
\hline & Group 2 & 858.9865 & $0.07 \%$ & 86 & 1200 \\
\hline & Group 3 & 858.8145 & $0.05 \%$ & 86 & 1200 \\
\hline & Group 4 & 859.3741 & $0.06 \%$ & 81 & 1200 \\
\hline \multirow{4}{*}{ Scenario 4} & Group 1 & 884.1374 & $0.05 \%$ & 68 & 1200 \\
\hline & Group 2 & 885.0898 & $0.09 \%$ & 59 & 1200 \\
\hline & Group 3 & 885.0071 & $0.03 \%$ & 60 & 1200 \\
\hline & Group 4 & 885.7371 & $0.06 \%$ & 60 & 1200 \\
\hline \multirow{4}{*}{ Scenario 5} & Group 1 & 862.0137 & $0.01 \%$ & 104 & 1200 \\
\hline & Group 2 & 862.7458 & $0.08 \%$ & 101 & 1200 \\
\hline & Group 3 & 862.5438 & $0.07 \%$ & 101 & 1200 \\
\hline & Group 4 & 863.2011 & $0.17 \%$ & 102 & 1200 \\
\hline
\end{tabular}

Table 12 presents the locations and installed capacities of the terminals in each scenario and each group of batteries to supply the total demand. The hyphen means that no terminal has been installed at the respective location. As the five scenarios of demand created by the Monte Carlo method presented the relative variation inherent to their stochastic process, it was expected that some differences would be identified between each scenario. It should be noted, however, that within the same scenario, the location decisions for installing the terminals were practically the same in the four groups. The only exception was scenario 1 , Group 2, where the model chose not to install at point 9 but at point 30, differing from the other groups in that scenario. This exception can be easily justified, as in scenario 1 , the demand for withdrawals at points 9 and 30 was the same. In some cases, variations in the capacity of the terminals can be identified in the same scenario, which can be attributed to the differences in the charging time of each group that lead the model to decide for battery reallocations instead of increasing capacity to meet a specific demand. Table 13 illustrates this dynamic showing the reallocation of batteries between local " $\mathrm{i}$ " and local " $\mathrm{j}$ " over the time with batteries in the configuration of Group 1, demand scenario 1. It is important to note that as a parameter of the model an upper bound of 400 batteries was assumed for supplying the network (Tbmax), but the results indicate that a maximum number of 104 batteries used in scenario 5 and group 1 is sufficient to supply the demand. 
Table 12. Model results: locations and capacity of installed terminals.

\begin{tabular}{|c|c|c|c|c|c|c|c|c|c|c|c|c|c|c|c|c|c|c|c|c|}
\hline \multirow{2}{*}{$\begin{array}{c}\text { Local ID } \\
\#\end{array}$} & \multicolumn{4}{|c|}{$\begin{array}{l}\text { Terminals Capacity } \\
\text { (Demand Scenario 1) }\end{array}$} & \multicolumn{4}{|c|}{$\begin{array}{l}\text { Terminals Capacity } \\
\text { (Demand Scenario 2) }\end{array}$} & \multicolumn{4}{|c|}{$\begin{array}{l}\text { Terminals Capacity } \\
\text { (Demand Scenario 3) }\end{array}$} & \multicolumn{4}{|c|}{$\begin{array}{l}\text { Terminals Capacity } \\
\text { (Demand Scenario 4) }\end{array}$} & \multicolumn{4}{|c|}{$\begin{array}{c}\text { Terminals Capacity } \\
\text { (Demand Scenario 5) }\end{array}$} \\
\hline & G1 & G2 & G3 & G4 & G1 & G2 & G3 & G4 & G1 & G2 & G3 & G4 & G1 & G2 & G3 & G4 & G1 & G2 & G3 & G4 \\
\hline 1 & 6 & 5 & 5 & 5 & 10 & 10 & 10 & 10 & 10 & 10 & 10 & 10 & 10 & 10 & 10 & 10 & 10 & 10 & 10 & 10 \\
\hline 2 & - & - & - & - & - & - & - & - & - & - & - & - & - & - & - & - & - & - & - & - \\
\hline 3 & - & - & - & - & 3 & 3 & 3 & 3 & - & - & - & - & 5 & 5 & 5 & 5 & 5 & 10 & 10 & 10 \\
\hline 4 & - & - & - & - & - & - & - & - & - & - & - & - & - & - & - & - & - & - & - & - \\
\hline 6 & - & - & - & - & - & - & - & - & - & - & - & - & - & - & - & - & - & - & - & - \\
\hline 7 & - & - & - & - & - & - & - & - & - & - & - & - & - & - & - & - & - & - & - & - \\
\hline 8 & - & - & - & - & - & - & - & - & 2 & 3 & 3 & 2 & 5 & 5 & 5 & 3 & 5 & 3 & 3 & 3 \\
\hline 9 & 3 & - & 3 & 3 & 3 & 3 & 3 & 3 & - & - & - & - & 3 & 2 & 2 & 3 & 2 & 2 & 2 & 2 \\
\hline 10 & 2 & 2 & 2 & 2 & - & - & - & - & 10 & 10 & 10 & 10 & - & - & - & - & 3 & 3 & 3 & 3 \\
\hline 11 & 8 & 6 & 6 & 8 & 5 & 3 & 3 & 3 & 6 & 10 & 10 & 5 & 6 & 10 & 6 & 5 & 10 & 10 & 10 & 10 \\
\hline 13 & 5 & 5 & 5 & 5 & 5 & 5 & 5 & 5 & 3 & 3 & 3 & 3 & 3 & 3 & 3 & 3 & 10 & 10 & 10 & 10 \\
\hline 14 & 3 & 3 & 3 & 3 & 5 & 5 & 5 & 5 & - & - & - & - & 3 & 3 & 3 & 3 & - & - & - & - \\
\hline 15 & 3 & 2 & 2 & 2 & 3 & 3 & 3 & 3 & 10 & 5 & 5 & 5 & - & - & - & - & - & - & - & - \\
\hline 16 & - & - & - & - & - & - & - & - & - & - & - & - & - & - & - & - & - & - & - & - \\
\hline 17 & - & - & - & - & - & - & - & - & - & - & - & - & - & - & - & - & - & - & - & - \\
\hline 18 & 6 & 5 & 5 & 5 & 5 & 3 & 3 & 5 & 3 & 3 & 3 & 3 & 3 & 3 & 3 & 3 & 10 & 5 & 5 & 5 \\
\hline 19 & - & - & - & - & - & - & - & - & - & - & - & - & - & - & - & - & - & - & - & - \\
\hline 20 & 5 & 3 & 3 & 3 & 10 & 10 & 10 & 10 & 3 & 3 & 3 & 3 & 10 & 3 & 3 & 5 & 10 & 10 & 10 & 10 \\
\hline 21 & - & - & - & - & - & - & - & - & 2 & 2 & 2 & 3 & 2 & 2 & 2 & 2 & - & - & - & - \\
\hline 22 & - & - & - & - & - & - & - & - & - & - & - & - & - & - & - & - & - & - & - & - \\
\hline
\end{tabular}


Table 12. Cont.

\begin{tabular}{|c|c|c|c|c|c|c|c|c|c|c|c|c|c|c|c|c|c|c|c|c|}
\hline \multirow{2}{*}{$\begin{array}{c}\text { Local ID } \\
\#\end{array}$} & \multicolumn{4}{|c|}{$\begin{array}{l}\text { Terminals Capacity } \\
\text { (Demand Scenario 1) }\end{array}$} & \multicolumn{4}{|c|}{$\begin{array}{l}\text { Terminals Capacity } \\
\text { (Demand Scenario 2) }\end{array}$} & \multicolumn{4}{|c|}{$\begin{array}{l}\text { Terminals Capacity } \\
\text { (Demand Scenario 3) }\end{array}$} & \multicolumn{4}{|c|}{$\begin{array}{l}\text { Terminals Capacity } \\
\text { (Demand Scenario 4) }\end{array}$} & \multicolumn{4}{|c|}{$\begin{array}{l}\text { Terminals Capacity } \\
\text { (Demand Scenario 5) }\end{array}$} \\
\hline & G1 & G2 & G3 & G4 & G1 & G2 & G3 & G4 & G1 & G2 & G3 & G4 & G1 & G2 & G3 & G4 & G1 & G2 & G3 & G4 \\
\hline 23 & 10 & 10 & 10 & 10 & 6 & 5 & 5 & 5 & 3 & 3 & 3 & 3 & 3 & 3 & 3 & 3 & 3 & 3 & 3 & 3 \\
\hline 24 & 10 & 10 & 10 & 10 & 10 & 10 & 10 & 10 & 5 & 5 & 5 & 3 & 10 & 10 & 10 & 10 & 10 & 10 & 10 & 10 \\
\hline 25 & - & - & - & - & - & - & - & - & - & - & - & - & - & - & - & - & - & - & - & - \\
\hline 26 & - & - & - & - & 2 & 2 & 2 & 2 & 10 & 10 & 10 & 10 & - & - & - & - & - & - & - & - \\
\hline 28 & - & - & - & - & 5 & 3 & 3 & 3 & 5 & 3 & 3 & 3 & 5 & 5 & 5 & 3 & 10 & 10 & 10 & 10 \\
\hline 29 & 3 & 3 & 3 & 3 & 2 & 2 & 2 & 2 & - & - & - & - & 3 & 3 & 3 & 5 & 10 & 10 & 10 & 10 \\
\hline 30 & - & 3 & - & - & - & - & - & - & - & - & - & - & - & - & - & - & - & - & - & - \\
\hline 31 & - & - & - & - & - & - & - & - & - & - & - & - & - & - & - & - & - & - & - & - \\
\hline 32 & - & - & - & - & - & - & - & - & - & - & - & - & - & - & - & - & - & - & - & - \\
\hline 33 & - & - & - & - & - & - & - & - & - & - & - & - & - & - & - & - & - & - & - & - \\
\hline 35 & 10 & 10 & 10 & 10 & 5 & 3 & 3 & 3 & 10 & 10 & 10 & 10 & 6 & 5 & 5 & 5 & 3 & 3 & 3 & 3 \\
\hline 36 & - & - & - & - & - & - & - & - & 5 & 5 & 5 & 5 & - & - & - & - & - & - & - & - \\
\hline 37 & 3 & 5 & 5 & 5 & 3 & 3 & 3 & 3 & 10 & 10 & 10 & 10 & 5 & 5 & 5 & 5 & 10 & 10 & 10 & 10 \\
\hline 38 & 5 & 5 & 5 & 5 & 5 & 5 & 5 & 5 & 10 & 10 & 10 & 10 & 5 & 5 & 5 & 3 & 10 & 10 & 10 & 10 \\
\hline 39 & 10 & 8 & 8 & 8 & 10 & 10 & 10 & 10 & 10 & 10 & 10 & 10 & 10 & 5 & 10 & 10 & 2 & 2 & 2 & 2 \\
\hline 40 & - & - & - & - & - & - & - & - & - & - & - & - & - & - & - & - & - & - & - & - \\
\hline 41 & - & - & - & - & 3 & 3 & 3 & 3 & - & - & - & - & - & - & - & - & 5 & 5 & 5 & 5 \\
\hline 42 & 2 & 2 & 2 & 2 & - & - & - & - & - & - & - & - & - & - & - & - & - & - & - & - \\
\hline
\end{tabular}


Table 13. Reallocation of batteries between local "i" and "j" over time with batteries in Group 1 and demand scenario 1.

\begin{tabular}{|c|c|c|c|c|c|c|c|c|c|c|c|c|c|c|c|c|c|c|c|c|c|}
\hline & & \multicolumn{20}{|c|}{ Time Period (t) } \\
\hline \multicolumn{2}{|c|}{ Local } & 1 & 4 & 5 & 6 & 12 & 19 & 23 & 25 & 27 & 29 & 31 & 32 & 33 & 34 & 35 & 37 & 38 & 39 & 41 & 45 \\
\hline $\mathbf{i}$ & $\mathbf{j}$ & & & & & & & & & & & & & & & & & & & & \\
\hline 1 & 10 & & & & & & & & & & & & & & & & & & 1 & & \\
\hline 5 & 37 & & & & & & & & & & & & & & & & & & & 1 & \\
\hline \multirow[t]{2}{*}{9} & 12 & & & & & & & & & & & & & & & & & 1 & & & \\
\hline & 38 & & & & & & & & & & & & & & & & & & 1 & & \\
\hline \multirow[t]{3}{*}{10} & 29 & & & & & & & & & & & 1 & & & & & & & & & \\
\hline & 35 & & & & & & 1 & & & & & & & & & & & & & & \\
\hline & 39 & 1 & & & & & & & & & & & & & & & & & & & \\
\hline \multirow[t]{3}{*}{11} & 10 & & & & & & & & & & & & & 1 & & & 1 & & & & \\
\hline & 12 & & & & & & & & & 1 & & & & & & & & & & & \\
\hline & 13 & & & & & & & & & & & 1 & & & & & 1 & & & & \\
\hline \multirow[t]{3}{*}{12} & 11 & & & & & 1 & & & & & & & & & & & & & & & \\
\hline & 14 & & 1 & & & & & & & & & & & & & & & & & & \\
\hline & 42 & 1 & & & & & & & & & & & & & & & & & & & \\
\hline 14 & 37 & & & & & & & & & & & & & & & & & & & & 1 \\
\hline 18 & 35 & & & & & & & 1 & & & & & & & & & & & & & \\
\hline 20 & 34 & & & & 1 & & & & & & & & & & & & & & & & \\
\hline
\end{tabular}


Table 13. Cont

\begin{tabular}{|c|c|c|c|c|c|c|c|c|c|c|c|c|c|c|c|c|c|c|c|c|c|}
\hline & & \multicolumn{20}{|c|}{ Time Period (t) } \\
\hline \multicolumn{2}{|c|}{ Local } & 1 & 4 & 5 & 6 & 12 & 19 & 23 & 25 & 27 & 29 & 31 & 32 & 33 & 34 & 35 & 37 & 38 & 39 & 41 & 45 \\
\hline i & $\mathbf{j}$ & & & & & & & & & & & & & & & & & & & & \\
\hline \multirow[t]{5}{*}{23} & 15 & & & & & & & & & & & & & & & 1 & & & & & \\
\hline & 24 & & & & & & & & & & & & & & & & & 1 & & & \\
\hline & 34 & & & & & & & & & & & & & & & & 1 & & & & \\
\hline & 39 & & & & & & & & & & & & 1 & & & & & & 1 & & \\
\hline & 42 & & & & & & & & 1 & & & & & & & & & & & & \\
\hline \multirow[t]{2}{*}{24} & 13 & & & & & & & & & & 1 & & & & & & & & & & \\
\hline & 18 & & & & & & & & & & & 1 & & & & & & & & & \\
\hline 37 & 38 & 1 & & & & & & & & & & & & & & & & & & & \\
\hline \multirow[t]{2}{*}{39} & 12 & & & & & & & & & & 1 & & & & & & & & & & \\
\hline & 38 & & & & & & & 1 & & & & & & & 1 & & 1 & & 1 & & \\
\hline 42 & 11 & & & & & & & & & & & & & & & & & & & & 1 \\
\hline
\end{tabular}


Table 14 presents the network locations in descending order according to the total of installations implemented in the 20 executions of the model and the average capacity of the terminals. It is important to note that as a parameter of the model, a maximum capacity of 36 slots per terminal was assumed, but the results indicate that a maximum capacity of 10 slots was sufficient to supply the demand. The results can be used as a reference to support the decision of select the best points within the network to install the terminals and define its capacity.

Table 14. Model results: Local ID, total installations, and average terminal capacity over twenty model executions.

\begin{tabular}{|c|c|c|c|c|}
\hline \#Ranking & \#Local ID & Local Type & $\begin{array}{l}\text { Number of Instalations } \\
\text { in } 20 \text { Model Executions }\end{array}$ & $\begin{array}{c}\text { Terminal Capacity } \\
\text { (Average) }\end{array}$ \\
\hline 1 & 1 & Fitness Center & 20 & 9.1 \\
\hline 2 & 11 & University & 20 & 7.0 \\
\hline 3 & 13 & University & 20 & 5.2 \\
\hline 4 & 18 & Gas Station & 20 & 4.3 \\
\hline 5 & 20 & Gas Station & 20 & 6.4 \\
\hline 6 & 23 & University & 20 & 4.9 \\
\hline 7 & 24 & Bar/Restaurant & 20 & 8.9 \\
\hline 8 & 35 & Bar/Restaurant & 20 & 6.4 \\
\hline 9 & 37 & $\begin{array}{c}\text { Shop in } \\
\text { transport station }\end{array}$ & 20 & 6.5 \\
\hline 10 & 38 & Bar/Restaurant & 20 & 6.9 \\
\hline 11 & 39 & Bar/Restaurant & 20 & 7.9 \\
\hline 12 & 5 & Bar/Restaurant & 16 & 4.7 \\
\hline 13 & 28 & Firm/Cowork & 16 & 5.4 \\
\hline 14 & 29 & Bar/Restaurant & 16 & 4.6 \\
\hline 15 & 34 & Gas Station & 16 & 2.6 \\
\hline 16 & 9 & Bar/Restaurant & 15 & 2.6 \\
\hline 17 & 3 & Touristic Spot & 12 & 5.6 \\
\hline 18 & 8 & Bar/Restaurant & 12 & 3.5 \\
\hline 19 & 10 & Firm/Cowork & 12 & 5.0 \\
\hline 20 & 14 & University & 12 & 3.7 \\
\hline 21 & 15 & University & 12 & 3.8 \\
\hline 22 & 12 & University & 8 & 7.6 \\
\hline 23 & 21 & Gas Station & 8 & 2.1 \\
\hline 24 & 26 & Shopping Center & 8 & 6.0 \\
\hline 25 & 41 & Bar/Restaurant & 8 & 4.0 \\
\hline 26 & 36 & Bar/Restaurant & 4 & 5.0 \\
\hline 27 & 42 & Shopping Center & 4 & 2.0 \\
\hline 28 & 30 & Supermarket & 1 & 3.0 \\
\hline 29 & 2 & Bar/Restaurant & 0 & 0.0 \\
\hline 30 & 4 & Touristic Spot & 0 & 0.0 \\
\hline
\end{tabular}


Table 14. Cont.

\begin{tabular}{ccccc}
\hline \#Ranking & \#Local ID & Local Type & $\begin{array}{c}\text { Number of Instalations } \\
\text { in 20 Model Executions }\end{array}$ & $\begin{array}{c}\text { Terminal Capacity } \\
\text { (Average) }\end{array}$ \\
\hline 31 & 6 & Shopping Center & 0 & 0.0 \\
\hline 32 & 7 & Bar/Restaurant & 0 & 0.0 \\
\hline 33 & 16 & Firm/Cowork & 0 & 0.0 \\
\hline 34 & 17 & Gas Station & 0 & 0.0 \\
\hline 35 & 19 & Gas Station & 0 & 0.0 \\
\hline 36 & 22 & Shopping Center & 0 & 0.0 \\
\hline 37 & 25 & Firm/Cowork & 0 & 0.0 \\
\hline 39 & 27 & Shopping Center & 0 & 0.0 \\
\hline 40 & 31 & Supermarket & 0 & 0.0 \\
\hline 41 & 32 & Gas Station & 0 & 0.0 \\
\hline 42 & 33 & Gas Station & 0 & 0.0 \\
\hline
\end{tabular}

\section{Discussion}

The experimental results suggest that the network performance using batteries in the fastest charging configuration (Group 4, with an electrical voltage of 4.1 Volts and an electrical current of 3.0 Ampere) tends to have a positive impact on their efficiency and profitability. Although the difference in profit is small between the four different battery groups, it should be noted that the experiment simulates only one day of operation on a small network, limited to the installation of a maximum of 20 terminals. In long-term operation and with the expansion of both the network and the customers number, the differences in profit obtained in the model tend to become more significant.

The proposed model presents the optimal points for installing the terminals on the network, the capacity of each terminal installed, the number of batteries needed to supply the network, and the number of batteries to be reallocated between each point over the period. Among the locations selected for installation of the terminals, the following stand out: fitness center, public transport terminal, bar and restaurant, tourist spot, and university. In addition to economic performance, the results related to the network sizing and operation are an important output to be evaluated. The average capacity of the installed terminals varied from 3 to 10 battery slots, far below the upper limit parameter of 36 slots. The average number of batteries for supplying the network with 20 terminals was 76 batteries, far below the upper limit parameter of 400 batteries.

The results show intense reallocation of batteries between terminals during the operation and also significant variations between scenarios, as shown in Table 13. This highlights the fact that while seeking to minimize the most significant costs, such as maintenance costs, capacity of terminals, and depreciation of batteries, the model tries to reallocate batteries between terminals in order to optimize network performance. Performing new experiments by varying the parameters of reallocation, maintenance, and depreciation costs can be useful to identify more profitable configurations of the system.

The results of laboratory tests with the measurement of battery performance in four groups with different voltage and electric current configurations were important inputs of the optimization model, enabling the evaluation of the best configurations for the network performance and generating significant differences in its results. New laboratory tests with batteries in different technical standards can be useful to identify more profitable configurations on the network and guide technological investments in battery development. 
Regarding the stochastic characteristic of demand, it is suggested as a future perspective to use a greater number of demand scenarios so that more experiments can be carried out, enabling a broader analysis of the network performance. Another extension for this work is to consider metaheuristic methods to solve larger instances.

\section{Conclusions}

In this paper, we have introduced the mobile battery network for electronic devices through energy banks and proposed an optimization model, which combines some literature elements related to electric vehicle networks and bicycle-sharing networks, including new components designed specifically for this new problem. A mixed integer programming model (MIP) was developed, combining strategic network location and sizing decisions (where to install and the capacity of the terminals) with operational decisions (allocation and reallocation of batteries at the terminals). Laboratory tests with lithium-ion batteries similar to those used in the network were carried out in four different voltage and electric current configurations to measure the degradation rate and the performance of the batteries in terms of charge and discharge time. These results are embedded into the model as the parameters of the depreciation rate and the batteries charging and discharging times. The model was applied in a case study using real data collected by a network of terminals located in the city of Rio de Janeiro. The experimental results provide insights for the network management and indicate that the network performance using batteries in the fastest charging configuration tends to have a positive impact on their efficiency and profitability.

The model can be used as a reference for other applications, such as electric vehicle networks optimization, especially those network that use small vehicles, have a large capillarity and use battery terminals. In addition, this model can be applied in a range of other applications that require the optimization of points that enable the use of mobile batteries, such as scooters, electric bicycles, drones, and wearable devices, among others.

Author Contributions: Conceptualization, L.E.C.M., R.F.C., D.R.L. and H.M.V.R.; methodology, L.E.C.M., R.F.C., D.R.L. and H.M.V.R.; software, L.E.C.M.; validation, L.E.C.M., R.F.C., D.R.L. and H.M.V.R.; formal analysis, L.E.C.M., R.F.C., D.R.L., H.M.V.R., R.S.D.T. and R.S.V.; investigation, L.E.C.M., R.F.C., D.R.L., H.M.V.R., R.S.D.T. and R.S.V.; resources, R.F.C.; data curation, L.E.C.M., R.S.D.T. and R.S.V.; writing—original draft preparation, L.E.C.M.; writing—review and editing, L.E.C.M., R.F.C., D.R.L. and H.M.V.R.; visualization, L.E.C.M., R.F.C., D.R.L. and H.M.V.R.; supervision, L.E.C.M., R.F.C. and H.M.V.R.; project administration, R.F.C.; funding acquisition, R.F.C. All authors have read and agreed to the published version of the manuscript.

Funding: This research was funded by the Development and Research Program of ANEEL in partnership with ENEL Rio Enterprise (PD-00383-0060/2017). The authors thank for the financial support provided by the Brazilian funding agencies CNPq, CAPES, FINEP, and FAPERJ. This study was partly financed in part by the Coordenação de Aperfeiçoamento de Pessoal de Nível SuperiorBrasil (CAPES)—Finance Code 001.

Institutional Review Board Statement: Not applicable.

Informed Consent Statement: Not applicable.

Data Availability Statement: A dataset containing the distance matrix and instances of five demand scenarios used in the article is available online in the Harvard Dataverse repository under the title "Powerbank Network Instance Files". https:/ / doi.org/10.7910/DVN/7FOWSW (accessed on 20 November 2021).

Acknowledgments: We thanks CAPES and PUC-Rio University for the research support.

Conflicts of Interest: The authors declare no conflict of interest. The funders had no role in the design of the study; in the collection, analyses, or interpretation of data; in the writing of the manuscript, or in the decision to publish the results. 


\section{References}

1. Lacy, P.; Rutqvist, J. The Product as a Service Business Model: Performance over Ownership. In Waste to Wealthl; Palgrave Macmillan: London, UK, 2015.

2. Frade, I.; Ribeiro, A. Bike-sharing stations: A maximal covering location approach. Transp. Res. Part A Policy Pract. 2015, 82, 216-227. [CrossRef]

3. You, N.; Ghamami, M. A corridor-centric approach to planning electric vehicle charging infrastructure. Transp. Res. Part B 2013, 57, 172-190.

4. $\quad$ Mak, H.; Rong, Y.; Shen, Z.M. Infrastructure Planning for Electric Vehicles with Battery Swapping. Manag. Sci. 2013, 59, 1557-1575. [CrossRef]

5. Xiang, Y.; Zhang, Y. Optimal Location of Charging Station of Electric Bus in Battery Replacement Mode. In International Symposium for Intelligent Transpotation and Smart City (ITASC) 2017 Proceedings; Smart Innovation, Systems and Technologies; Springer: Singapore, 2017; Volume 62.

6. Schiffer, M.; Walther, G. An Adaptive Large Neighborhood Search for the Location-routing Problem with Intra-route Facilities Transp. Sci. 2018, 52, 229-496. [CrossRef]

7. Yang, J.; Guo, F.; Zhang, M. Optimal planning of swapping/charging station network with customer satisfaction. Transp. Res. Part E 2017, 103, 174-197. [CrossRef]

8. Chen, Y.; Chen, C.; Li, S.; Yu, C. Location optimization for multiple types of charging stations for electric scooters. Appl. Soft Comput. 2018, 67, 519-528. [CrossRef]

9. Lin, J.R.; Yang, T.H.; Chang, Y.C. A hub location inventory model for bicycle sharing system design: Formulation and solution. Comput. Ind. Eng. 2013, 65, 77-86. [CrossRef]

10. Park, C.; Sohn, S.Y. An optimization approach for the placement of bicycle-sharing stations to reduce short car trips: An application to the city of Seoul. Transp. Res. Part A 2017, 105, 154-166. [CrossRef]

11. Zhang, D.; Yu, C.; Desai, J.; Lau, H.Y.K.; Srivathsan, S. A time-space network flow approach to dynamic repositioning in bicycle sharing systems. Transp. Res. Part B 2017, 103, 188-207. [CrossRef]

12. Maggioni, F.; Cagnolari, M.; Bertazzi, L.; Stein, W.W. Stochastic optimization models for a bike-sharing problem with transshipment. Eur. J. Oper. Res. 2019, 276, 272-283. [CrossRef]

13. Hannan, M.A.; Lipu, M.S.H.; Hussain, A.; Mohamed, A. A review of lithium-ion battery state of charge estimation and management system in electric vehicle applications: Challenges and recommendations. Renew. Sustain. Energy Rev. 2017, 78, 834-854. [CrossRef]

14. Deng, Z.; Hu, X.; Lin, X.; Xu, L.; Che, Y.; Hu, L. General discharge voltage information enabled health evaluation for lithium-ion batteries. IEEE/ASME Trans. Mechatron. 2021, 26, 1295-1306. [CrossRef]

15. Mit Eletric Vehicle Team. A Guide to Understanding Battery Specifications; Massachusetts Institute of Technology: Cambridge, MA, USA, 2008.

16. Deng, Z.; Hu, X.; Lin, X.; Che, Y.; Xu, L.; Guo, W. Data-driven state of charge estimation for lithium-ion battery packs based on Gaussian process regression. Energy 2020, 205, 118000. [CrossRef]

17. Battery University. BU-501, Basics about Discharging. 2017. Available online: https://batteryuniversity.com/learn/article/ discharge_methods (accessed on 15 October 2018).

18. Li, Z.; Huang, J.; Liaw, B.Y.; Zhang, J. On state-of-charge determination for lithium-ion batteries. J. Power Sources 2017, 348, 281-301. [CrossRef]

19. Kalawoun, J.; Biletska, K.; Suard, F.; Montaru, M. From a novel classification of the battery state of charge estimators toward a conception of an ideal one. J. Power Sources 2015, 279, 694-706. [CrossRef]

20. Hsieh, G.C.; Chen, L.R.; Huang, K.S. Fuzzy-Controlled Li-Ion Battery Charge System with Active State-of-Charge Controller. IEEE Trans. Ind. Electron. 2001, 48, 585-593. [CrossRef]

21. Teixeira, R.S.D.; Louzada, D.R.; Gusmão, L.A.P.; Calili, R.F. Development of a voltage curve prediction model for lithium-ion battery based on destructive tests. J. Phys. Conf. Ser. 2021, 1826, 012091. [CrossRef] 